\title{
AÇÕES DO LABORATÓRIO DE EDUCAÇÃO MATEMÁTICA E FÍSICA EM TEMPOS DE COVID-19
} ACTIONS OF THE MATHEMATICAL AND PHYSICAL EDUCATION LABORATORY IN COVID-19 TIMES

\author{
Janice Rubira Silva*a, Vanda Leci Bueno Gautérioa, Raquel Silveira da Silvaa , Caio Josa \\ Barbosa Theodosio
}

\author{
Universidade Federal do Rio Grande \\ *E-mail: janicerubira@hotmail.com
}

\section{RESUMO}

O presente artigo objetiva refletir sobre as experiências vivenciadas pela equipe do Laboratório de Educação Matemática e Física - LEMAFI - da Universidade Federal do Rio Grande - FURG ao produzir Objeto de Aprendizagem - OA - para um espaço de ensino não formal da 47a Feira do Livro e Objetos Virtuais de Aprendizagem - OVA para ensino remoto e disponibilizado na plataforma Google Classroom para os professores utilizarem em tempos de COVID-19. Para isso, utilizou-se o diário de pesquisa enquanto recurso metodológico para a prática de pesquisa qualitativa e dedicou-se a discutir as potencialidades da atividade O Tangram potencializando a (re)construção de conceitos geométricos como OA e também como OVA. Aborda-se a Metodologia Ativa como método que melhor atende as necessidades dos estudantes e finaliza-se, sinalizando para a importância da contínua reflexão para a proposição de alternativas pedagógicas capazes de potencializar o ensinar e o aprender a partir dos distintos contextos socioculturais vivenciados.

Palavras-chave: Objetos Virtuais de Aprendizagem; ação pedagógica; ensino remoto.

\section{ABSTRACT}

This article aims to reflect on the experiences lived by the team of the Laboratory of Mathematical and Physical Education - LEMAFI - of the Federal University of Rio Grande - FURG when producing a Learning Object - OA - for a non-formal teaching space of the 47th Book Fair and Virtual Learning Objects - OVA - for remote teaching and made available on the Google Classroom platform for teachers to use in COVID-19 times. For this, the research diary was used as a methodological resource for the practice of qualitative research and was dedicated to discussing the potential of the Tangram activity, potentiating the (re) construction of geometric concepts such as OA and also as OVA. Active Methodology is approached as a method that best meets the needs of students and ends, signaling the importance of continuous reflection for proposing pedagogical alternatives capable of enhancing teaching and learning from the different socio-cultural contexts experienced.

Keyword: Virtual Learning Objects; pedagogical action; remote teaching. 


\section{INTRODUÇÃO}

A adequação das ações pedagógicas no âmbito escolar aos atuais processos construtivos do saber é um dos desafios que já se apresentavam aos professores nos últimos tempos, em específico aos professores de Matemática. De um lado tem-se os estudantes nativos digitais (PRENSKI, 2001) que possuem a autonomia para a construção do conhecimento a partir das informações do seu interesse, de outro a grande parte dos docentes que se constituíram como profissionais a partir de um modelo escolar centrado na cientificidade e distante do viver (TARDIF, 2014).

Ambas condições estabelecem distintas relações com o saber que são gradativamente alteradas a partir das mudanças contemporâneas, o que torna necessária a atualização dos conhecimentos e competências do professor para qualificar seu trabalho. Sendo assim, a equipe do Laboratório de Educação Matemática e Física - LEMAFI - da Universidade Federal do Rio Grande FURG vem, desde 2011, desenvolvendo ações de incentivo ao ensino, à pesquisa e extensão, integrando as áreas de Educação Matemática e Física, contribuindo para o processo de qualificação do professor em formação inicial ou continuada, aproximando a Universidade das escolas de Educação Básica.

No ano de 2020, o LEMAFI começou suas atividades em 29 de janeiro, no Balneário Cassino na cidade do Rio Grande, localizado no litoral sul gaúcho através da sua participação na $47^{\mathrm{a}}$ Feira do Livro da FURG. Durante as onze noites, em um evento cultural comercial voltado para a convivência, o despertar do prazer pela leitura e propagação do conhecimento, proporcionou à comunidade a participação na atividade "Rotações por Estações de Aprendizagem: a construção do conhecimento pela exploração, interpretação e resolução de problema".

A partir dos resultados alcançados na feira, projetou-se algumas ações para o início do ano letivo. No entanto, a necessidade do distanciamento social e suspensão das aulas nas escolas e universidades, devido à progressão do surto da Coronavírus Disease 2019 (COVID-19), tornou necessário pensar em alternativas do ensinar e do aprender para garantir aos estudantes o contato com os saberes escolares em meio nova organização social e cultural que se estabeleceu.

Nessa direção, são apresentadas e discutidas nesse trabalho as compreensões construídas pela equipe do LEMAFI, autores deste manuscrito, ao produzir os Objetos de Aprendizagem - OA - para um espaço de ensino não-formal da $47^{\mathrm{a}}$ Feira do Livro ${ }^{1}$ e os Objetos
Virtuais de Aprendizagem - OVA - para o ensino remoto à emergência. Essa modalidade de ensino se difere do Ensino a Distância em que as aulas são planejadas e projetadas para serem on-line, o ensino remoto à emergência é uma mudança temporária, uma forma de trabalho alternativo devido a circunstâncias de crise (HODGES et al, 2020). Tais experiências emergem ao nos (re)organizamos para dar continuidade às atividades no período de paralisação das aulas presenciais, ocasionadas pela COVID - 19 .

Sendo assim, a partir da análise reflexiva do diário de pesquisa "considerando-o como tecnologia para a prática de pesquisa qualitativa" (ARAÚJO et al, 2013 , p. 54) e sustentado no entendimento de que o método qualitativo se aplica aos estudos que são "produtos das interpretações que os humanos fazem a respeito de como vivem, constroem seus artefatos e a si mesmos, sentem e pensam" (MINAYO, 2010, p. 57), apresentamos nas seções a seguir, as ações do LEMAFI. Tecemos considerações com relação ao potencial dos Objetos de Aprendizagem, virtuais ou não, como instrumento que possibilita a ação educativa (VIGORITO, GAUTÉRIO, 2018), bem como refletimos sobre o fazer docente e a produção de alguns materiais pedagógicos para serem empregados de forma presencial e/ou remota. Por fim, as compreensões construídas destacando a importância de ações alternativas, da reflexão sobre o nosso operar criativo, dinâmico e coerente aos processos de construção do conhecimento Matemático em tempos de isolamento social.

\section{AÇÕES DO LEMAFI}

Entendemos que o educar ocorre em diversos espaços, visto que a educação não se limita aos saberes escolarizados, outros saberes se fazem fundamentais para a construção de habilidades e competências que concedam ao indivíduo autonomia e senso crítico, condições necessárias para compreender e agir sobre o mundo em que vive. Entretanto, a formação oferecida pelas instituições de ensino superior no processo de formação inicial docente, apesar de fundamental, não é suficiente para o exercício de sua profissão (TARDIF, 2014). Neste sentido, percebemos a relevância das práticas formativas dos docentes utilizando-se da teoria e da prática.

De acordo com o artigo 83 do Regimento Geral da Universidade Federal do Rio Grande - FURG (Resolução 015/09, de 26/06/2009 do CONSUN), “a 
extensão universitária constitui-se em atividade de natureza acadêmica, que viabiliza a integração com a sociedade, visando a promover a formação, a transformação da realidade e a produção compartilhada de saberes entre ambas". Dessa forma, a universidade representada pelo LEMAFI, se apresenta como um espaço dialógico reflexivo para (re)pensar à docência, seus saberes e fazeres, de democratização do conhecimento, promovendo uma mudança de percepção entre os participantes.

No LEMAFI, professores das escolas de educação básica da rede municipal do Rio Grande/RS, em constante formação, juntamente com os licenciandos e professores da universidade, dialogam buscando pensar os processos do ensinar e do aprender Matemática e Física. Segundo Rêgo e Rêgo (2012) quando o Laboratório de Ensino de Matemática é instalado em instituições de ensino superior, possibilita o estreitamento das relações entre a instituição e a comunidade, a qualificação do ensino e implementação de uma cultura de base científica.

Ampliamos a compreensão de laboratório de ensino e definimos o LEMAFI como laboratório de educação, pois nosso objetivo é construir conhecimento e qualificar o ensinar e o aprender, garantindo a relevância do respeito ao outro como legítimo (MATURANA, 2002), valorizando e resgatando os valores humanos e sociais. Além disso, buscamos legitimar ao longo das atividades, as diferentes experiências, bem como, formas de ser e agir as quais são compartilhadas, através das interações, com respeito a singularidade dos sujeitos.

Nesse processo, ao entender que as atividades de extensão corroboram com os objetivos do LEMAFI, a Secretaria de Município da Educação do Rio Grande SMEd, do estado do Rio Grande do Sul, a qual busca a "atualização e aperfeiçoamento aos professores e especialistas" (Lei Orgânica, Art. 161, 02 de abril de 1990) celebra um convênio entre a mesma e a FURG. Assim, a Rede Municipal de Ensino disponibiliza duas professoras $^{2}$, ambas com formação em Matemática Licenciatura Plena e Pedagogia para, juntamente com os acadêmicos bolsistas, comporem a equipe e desenvolverem atividades de pesquisa e extensão.

A partir dessa parceria, as ações pedagógicas recorrentes são realizadas no âmbito do LEMAFI e nos ambientes escolares, sejam com professores em formação continuada e/ou estudantes. As ações consistem em promover experiências matemáticas construtivistas, bem como de práticas que mobilizem a cognição e o desenvolvimento de habilidades (LORENZATO, 2012). Um processo do aprender, que para Moran (2018), ocorre pelo questionamento e experimentação permitindo o avanço de níveis mais simples para os mais complexos de conhecimentos.

Nesse sentido, a construção dos saberes acontece na ação e na prática o que leva a ressignificação do papel do professor que passa a ser responsável por "[...] ajudar os alunos a irem além de onde conseguiriam ir sozinhos, motivando, questionando, orientando (MORAN, 2018, p. 38). Além disso, no contexto educacional emergente no qual estamos inseridos, educar exige pensarmos em estratégias para (re)encantarmos os estudantes que, imersos em uma cultura digital, têm a seu acesso um grande fluxo de informações advindas de distintas fontes que, por muitas vezes, os tornam consumidores com baixo letramento informacional, levando a descrença quanto ao ensinar e aprender, pois a "cultura digital modela as formas de pensar, agir, comunicar-se com os outros, trabalhar e agir" (KENSKI, 2015, p. 01).

Nesse processo, uma das linhas de ação do LEMAFI compreende a elaboração, adaptação e uso de material pedagógico, seja os Objetos de Aprendizagem $\mathrm{OA}-$, material concreto e manipulativo que possibilita experimentos, a percepção da lógica utilizada nas fórmulas e os significados delas, criando o elo entre teoria/prática, minimizando as rupturas da articulação do cotidiano para o saber escolar e potencializando o aprender; ou os Objetos Virtuais de Aprendizagem OVA-, que consistem em recursos pedagógicos virtuais, de suporte multimídia e com linguagem hipermídia, que pode ser reutilizado com o intuito de potencializar a aprendizagem, por meio de atividades lúdicas e interativas (VIGORITO, GAUTÉRIO, 2018) e assim qualificar o ensinar e o aprender.

Percebemos o potencial dos OA e/ou OVA por compreendemos que a ação e a percepção estão em congruência, produzindo o esquema sensório-motor, constitutivo da corporalidade e da cognição. Maturana (2002) concebe a cognição como um fenômeno operatório dos seres vivos de modo congruente com suas circunstâncias. Ou seja, é no experienciar que o sujeito guia suas ações.

\section{Produção de Objetos de Aprendizagem e Objetos Virtuais de Aprendizagem em ações ativas}

$\mathrm{Na}$ busca por contemplar os aspectos indicados anteriormente, com "a oportunidade de avaliar na prática, sem as pressões do espaço formal tradicional da sala de aula, novos materiais e metodologias" (RÊGO, RÊGO, 2012, p. 41), e ainda imersos no aprender e nas potencialidades, principalmente, das Metodologias

${ }^{2}$ Autoras deste manuscrito. 
Ativas (MORAN, 2018; NEVES, MERCANTI, LIMA, 2018), mesmo frente ao ensino remoto à emergência buscamos garantir as aprendizagens essenciais, na Educação Básica de nosso município, através do atendimento das especificidades de cada nível e modalidade educacional, de acordo as proposições do Documento Orientador Curricular do Território Riograndino (2019, p. 11). Dentre elas, salientamos a elaboração, adaptação e uso de materiais pedagógicos para a realização de oficinas, uma estratégia que possibilita para além da experiência e produto final por dar espaço a reflexão sobre as ações.

Com a necessidade do distanciamento social, nos (re)inventamos, para o desenvolvimento de atividades. Partimos dos pressupostos teóricos das Sequências Didáticas, ou seja, atividades ordenadas e articuladas que compõem as Unidades Didáticas (ZABALA, 1998) para serem empregadas como atividades remotas à emergência, as quais instigam os professores e/ou estudantes a tomada de decisões e a elaborar estratégias. Intentamos, com essa proposição, romper com práticas descontextualizadas e desprovidas de significado apresentando outro fazer escolar, pautado na construção do conhecimento como um processo ativo. Assim, as atividades produzidas pelo LEMAFI, no momento em que vivenciamos a presença do novo coronavírus (SARS-CoV-2) possuem um tratamento especial em sua elaboração com o intuito de envolver os estudantes, pelo visual diferenciado e problematização dos conceitos, contribuindo para a construção do conhecimento matemático e promoção do pensamento crítico-reflexivo (ALMEIDA, 2017).

Sendo assim, o material desenvolvido pelo LEMAFI é um recurso didático, o qual dá suporte ao trabalho dos professores tanto durante a pandemia quanto no momento que retornarmos, como por exemplo, caso ele utilize-se dos pressupostos metodológicos do modelo invertido de sala de aula. Estudos (MUNHOZ, 2015; NEVES, MERCANTI, LIMA, 2018; BERGMANN, SAMS, 2020) mostram que esta metodologia pressupõe que seja disponibilizado previamente um material para leitura prévia, utilizando um Ambiente Virtual de Aprendizagem - AVA - ${ }^{3}$.

$\mathrm{Na}$ sala de aula, é o momento das perguntas e das argumentações, com o professor que pode organizar atividades em grupo, mediando e intervindo com outros recursos. O professor pode sugerir que o contato inicial com a informação seja feito por meio dos OVAs disponibilizados pelo LEMAFI. Tal objeto se destaca devido ao desenvolvimento da responsabilidade e autonomia do estudante em realizar seus estudos prévios, no próprio ritmo, tendo a opção de pausar e reproduzi-lo quantas vezes achar necessário.

Para Silva e Novello (2019, p. 3) para que a tecnologia contribua para o fazer pedagógico se faz necessário "[...] compreender as potencialidades dos recursos tecnológicos, através da troca, estudo e exploração e, se permitir, transformar seu saber-se e saber-fazer, a partir das Tecnologias Digitais, e assim modificar o ensinar e o aprender". Assim, ao produzir os OVA a equipe busca desafiar os estudantes a criarem seu próprio OA, fomentando experiências ativas em contextos híbridos, unindo "[...] as vantagens das metodologias indutivas e das metodologias dedutivas" (MORAN, 2018, p. 35) ao conciliar a experimentação com a dedução por meio da combinação físico-digital, atendendo a especificidades dos estudantes como uso de recursos tecnológicos, aulas dinâmicas, autonomia para a realização das atividades experimentais em tempos integrados. Ações próprias da natureza humana.

Segundo Lorenzato (2012) a experimentação é uma ação que assume o sentido de pôr a prova, ensaiar, verificar um determinado fenômeno, ou seja, investigar. $\mathrm{Na}$ escola, a experimentação é importante por possibilitar momentos propícios a motivação, desenvolvendo raciocínio lógico, reflexão e (re)construção do conhecimento. Para Moran (2018), os múltiplos espaços de experimentação disponíveis nos celulares ampliam a realidade (realidade aumentada), bem como a recriam (realidade virtual) e são acessíveis de qualquer lugar. Cabe à escola adaptar ou criar espaços de pesquisa, experimentação, produção, debate e síntese.

\section{Reflexões sobre as ações do LEMAFI}

Como mencionado acima, desde 2011, o LEMAFI busca desenvolver ações em que aproxime a Universidade das escolas de Educação Básica. Em 2017, com o advento da Base Nacional Comum Curricular (BNCC) nos sentimos contemplados com a proposição de valorizar as situações lúdicas de aprendizagem, com progressiva sistematização das experiências, um estudante ativo, percebendo o significado das fórmulas e cálculos. Em 2019, surge o Documento Orientador Curricular do Território Rio-grandino que constitui-se em um referencial alinhado à BNCC e às concepções dos professores de nosso município, documento que nos fortalece e nos embasa para o desenvolvimento das atividades com a criação e utilização de jogos e material didático.

Nesta perspectiva, o primeiro movimento para a proposição da ação pedagógica foi definir o contexto de
${ }^{3}$ Plataforma de software que possibilita criar espaços para o repositório e interações possuindo recursos como fórum, chats, hiperlinks, vídeo aula, tutoriais e etc., seu foco principal é a aprendizagem. 
trabalho, ou seja, as características do lócus educacional, suas peculiaridades e os conhecimentos almejados pela escola para, assim, determinar os objetivos que irão orientar a ação. Optou-se por utilizar os pressupostos teóricos da técnica de ensino híbrido rotações por estações (BACICH, NETO, TREVISANI, 2015) que consiste em um dos modelos utilizados por professores que optam por modificar a condução das aulas. Compreende o revezamento de atividades a serem realizadas de acordo como a orientação do professor ou com horário fixo. As tarefas envolvem discussões, com ou sem o professor, atividades escritas, leituras e, atividade on-line.

Assim, propomos as "Rotações por Estações de Aprendizagem: a construção do conhecimento pela exploração, interpretação e resolução de problema", uma possibilidade de ação pedagógica dinâmica em que os estudantes são divididos em equipes e convidados a participar de um circuito composto por diferentes atividades experimentais que contemplem as necessidades do grupo. Por estação encontram-se um professor/bolsista que apresenta o material empregado e propõe alguns desafios para resolverem em um intervalo de tempo, de 15 a 20 minutos, e que independem das atividades anteriores e/ou posteriori ${ }^{4}$.

Iniciado 2020, começamos nossas com as atividades de rotações pelas Estações de Aprendizagem: Gráficos na mídia, o uso de Formas e Cores, Blocos Lógicos, História dos Números, Torre de Hanói, Tangram, construção de Sólidos Geométricos, bem como a Física: a Viagem pelo espaço, Como enxergar sua voz e Brinque e crie com a música na $47^{\mathrm{a}}$ Feira do Livro da FURG. As ações desenvolvidas mostram que mesmo estando em um espaço educativo não formal, ambas áreas do conhecimento podem ser abordadas com atividades lúdicas por meio da utilização de OA, sem que haja prejuízo na abordagem conceitual.

No mês de março, período que começa o ano letivo, passamos a vivenciar uma nova realidade, devido a necessidade do distanciamento social. No entanto, do ponto de vista autopoiético, somos organismos vivos e autônomos, passamos por processos de transformação da nossa estrutura constantemente (MATURANA, 2002), que nos convidam a (re)pensar nossa cultura escolar e universitária. Para Silva e Camargo (2015) a atividade educativa é uma manifestação cultural, sendo assim constitui-se por rupturas, mudanças e transformações.

A pandemia causada pelo SARS-CoV-2, nos levou a interrupção das aulas presenciais e houve a

${ }^{4}$ No ano letivo de 2019 foram realizadas quarenta e uma atividades, as quais foram no espaço do LEMAFI e âmbito escolar.

${ }^{5}$ Um recurso do Google Apps desenvolvido, em 2014, para as escolas desenvolverem, compartilharem e avaliarem percepção das Tecnologias da Informação e Comunicação como ferramentas para minimizar o distanciamento entre professor-aluno-escola, surgindo a possibilidade da oferta de aulas remotas à emergência a um número expressivo de estudantes. No entanto, pensar pedagogicamente ações, que envolvam conceitos específicos da Matemática e Física, que conduzam os estudantes ao aprender autônomo, a partir da sua interação com as atividades propostas e, em muitos casos, sem o auxílio de um familiar, tornou-se um desafio.

Dessa forma, o grupo do LEMAFI se moveu para pesquisar, ousar e se reinventar como educadores e propor em ações que contemplem as especificidades deste momento. Partimos para a elaboração dos OVA, porém, contemplando o uso de $\mathrm{OA}$ e disponibilizado no AVA. Os Objetos de Aprendizagem, virtuais ou não, têm o potencial de estimular a reflexão e a percepção da aplicação dos conceitos em diversos contextos (VIGORITO, GAUTÉRIO, 2018), até mesmo com distanciamento social.

Salientamos que não temos a pretensão de que OVA substitua a aula do professor, a mediação pedagógica é importante, mas que componha o percurso didático e possibilite um ensino híbrido (BACICH, NETO, TREVISANI, 2015). Os OVA possuem a vantagem de interligar conceitos, de forma não linear e lúdica, tornando a aprendizagem ativa e desafiadora (MAZUR, 2015). Além disso, podem ser revisitados sempre que o estudante precisar, está na web e disponível para download e ser usado em diversos dispositivos e locais.

Para hospedar o material desenvolvido optamos por utilizar-se do AVA denominado Google Classroom ${ }^{5}$. No AVA, por enquanto, postamos as atividades direcionadas a Matemática, que estão distribuídas em quatro Unidades Didáticas: Geometria com dobraduras; O Tangram potencializando a (re)construção de conceitos geométricos; História da Álgebra: equações no cotidiano; Educação Estatística: Lemafinho em produção e análise dos dados. Todas disponibilizadas em sequências didáticas, respeitando o tempo de concentração dos estudantes (ZABALA, 1998).

Descreveremos nas próximas seções, uma atividade de Matemática ofertada em 2020 de forma presencial, a Estação de Aprendizagem titulada "O Tangram potencializando a (re)construção dos conceitos geométricos" e, que atualmente, foi reestruturada para compor uma das Unidades Didática para ser trabalhada

trabalhos pedagógicos. Disponível em

$<$ https://classroom.google.com/h>. O link de acesso (login) ao material é

$<$ https://classroom.google.com/u/0/c/NzUyMTc4MzY1NzNa $>$ e possui a chave (senha) 5 brx $7 \mathrm{ja}$. 
de forma remota à emergência, o que demanda cuidados com a sua estrutura didática e pedagógica, não é a transposição das aulas presenciais.

\section{O Tangram como material didático}

O trabalho com o jogo de Tangram, que identificamos como um OA, tem início no questionamento a respeito de sua origem, destacando a existência de diversas lendas relacionadas ao Tangram, bem como a sua ligação com a filosofia chinesa que associa as sete peças do Tangram a sete virtudes humanas: a paciência, a castidade, a generosidade, a temperança, a diligência, a caridade e a humildade. Segundo Morales et al (2016) o Tangram, também conhecido como "Sete Peças Inteligentes", teve a origem na Dinastia Chinesa Tang. Formado por sete figuras geométricas: dois triângulos grandes, um triângulo médio, dois triângulos pequenos, um quadrado e um paralelogramo. A construção e manipulação do jogo nos possibilita o diálogo e a proposição de análise de cada passo da atividade e das peças que compõem o material, no nosso caso, abordando conceitos específicos da Matemática com a intenção de desenvolver o raciocínio lógico matemático.

\section{O Objeto de Aprendizagem Tangram em uma atividade presencial}

Durante a atividade, que ocorreu no espaço da $47^{a}$ Feira do Livro, uma área ampla com exposição de diversos materiais didáticos e atividades práticas de Matemática e Física a Estação de Aprendizagem foi demarcada por alguns tatames e almofadas no chão, espaço que disponibilizamos os jogos de Tangram em madeira (espalhados), para quem tivesse o interesse de explorar o material, independente da idade ou escolaridade. A partir da curiosidade sobre o material ou desejo de manipular, um professor/bolsista estabelecia um diálogo com o visitante apresentando o jogo e destacando que o mesmo, nos possibilita explorar conceitos geométricos, como perímetro, área, as figuras geométricas que compõem o jogo, indagações sobre as quantidade de triângulos pequenos necessários para cobrir/sobrepor o quadrado dentre outros questionamentos, buscando validar os saberes anteriores. De acordo com seu entusiasmo, compreensão e realização dos desafios propostos, lançávamos novos questionamentos (LORENZATO, 2012; MAZUR, 2015; BACICH, TANZI NETO, TREVISANI, 2015).

O OA favorece os experimentos investigativos, estimulam a capacidade de abstração e o raciocínio lógico dedutivo (MORALES et al, 2016). Então, o sujeito era convidado a resolver um problema real, manipulando as peças do jogo. O professor/bolsista, utiliza-se de estratégias pedagógicas, mediando e relacionando as peças do jogo com terrenos, quadras, bairros, de forma que consigam fazer a transposição didática do OA para o cotidiano. Assim, buscamos exercitar o ver, ouvir, tocar e sentir. Promover momentos em que permita o aprender compartilhado, distantes da rigidez que legitimou-se como a única prática capaz de produzir conhecimento matemático.

\section{O Tangram como material didático para uma atividade remota}

Ao produzirmos e disponibilizarmos a atividade no Google Classroom a fim de contribuir para o ensino remoto, alteramos a forma de trabalho. Percebemos que os modos de produção de $\mathrm{OA}$ não poderiam ser abordados da mesma forma no contexto on-line, o que exigiu repensar nossas práticas e se (re)adaptar às mudanças da sociedade atual. Para Silveira, Fonseca e Laurino (2019), o operar dos artefatos tecnológicos podem originar uma mudança na cultura que não nega os artefatos anteriores, mas cria uma recorrência na forma de agir.

Passou-se a elaborar sequências didáticas voltadas aos estudantes dos Anos Finais, do Ensino Fundamental. Em um processo ativo de construção do conhecimento pela ação, os estudantes foram instigados a produzir o OA Tangram a partir do emprego de materiais como folha de papel ofício (tamanho A4) ou pedaço de EVA ou até mesmo uma barra de sabão para, de modo gradativo, ampliar seu conhecimento a respeito de conceitos matemáticos como: simetria de reflexão e rotação, os conceitos da geometria em relação à área e o volume dos objetos, o estudo do plano com relação ao ponto, as retas concorrentes, perpendiculares, paralelas, coincidentes, transversais, coplanares e reversas e outros.

Totalizando, foram produzidas nove sequências didáticas que compõem a unidade didática e que tem como objetivo a descoberta do saber e do entender dos conceitos da geometria por meio da experiência (LORENZATO, 2012). Consideramos que, a compreensão de conceitos abstratos da matemática por meio de ações como as propostas passam a ser significativas para o estudante. Partindo de situações vivenciadas e manipulando o material os ensinamos a pensar e ver o mundo matematicamente.

A unidade didática proposta desafia o professor, o levando a desconstruir as práticas escolares arraigadas histórico e culturalmente (SILVA, CAMARGO, 2015). Aquele que se coloca na posição de mediador do conhecimento e se assume como tal, estará desejoso de trazer mais qualidade de ensino para suas práticas 
pedagógicas.

\section{A transformação na convivência: da produção de $\mathrm{OA}$ para OVA}

O LEMAFI se constituiu como um espaço de convivência em que os professores, seja da Universidade ou da rede municipal, não são mais os mestres, mas parceiros, atores e autores; ajudam e apoiam os discentes/bolsistas em processo de formação. Para Maturana (2002) tanto os professores quanto os discentes, ao vivenciarem a experiência do ensinar e do aprender em um espaço em que todos participam, envolvem-se, trazem contribuições e as perturbações são mútuas, desencadeiam a transformação na convivência.

Estávamos em nossa zona de conforto, desenvolvendo os OA para uso da comunidade - no LEMAFI ou pelo sistema de empréstimo -, oficinas e as Estações de Aprendizagem para compor as Rotações que agendávamos previamente com a Secretaria de Município da Educação do Rio Grande, escolas e/ou universidade. Repentinamente, o desafio passa a produção de material para atividades remotas à emergência, e também dar assessoria aquele professor que deseja organizar seu material para o trabalho remoto visto que "[...] percebe-se que ainda existe uma grande maioria dos docentes que encontram dificuldades em utilizar esses recursos, e muitas vezes preferem continuar no modo "tradicional", o que não é interessante para o momento" (SILVA, 2017, p. 72).

Hodges et al (2020) destaca que os cursos online e a distância são resultantes de um trabalho minucioso, envolvem um bom design e planejamento instrucional para obter a qualidade necessária. Processo esse, ausente na maioria dos casos de mudanças de emergência. Tal fato revela temos entraves, mas são minimizados pela utilização de ferramentas, levando-nos a traçar novas perspectivas.

A educação básica, um direito público subjetivo e assegurado pela Constituição Federal - CF - de 1988, destacando no Art. $n^{\circ} 206$ que a educação precisa ser garantida para o pleno desenvolvimento, a partir de "igualdade de condições para o acesso e permanência na escola" (BRASIL, 1988). Maturana (2002) corrobora ao destacar que como seres humanos não vivemos sozinhos, pela história da humanidade se percebe que o amor e a cooperação estão associados à sobrevivência. É por esse motivo, entre outros tantos, que a educação básica precisa ser presencial, pois nas escolas aprendemos mais que conteúdos, aprendemos modos de vida.

Porém, neste momento o Estado exercerá seu dever oferecendo as atividades remotas, $\mathrm{o}$ artigo $\mathrm{n}^{\circ} 205$, da CF, define que "A educação, direito de todos e dever do Estado e da família, será promovida e incentivada com a colaboração da sociedade". (BRASIL, 1988), assim podemos contar com as famílias e a colaboração da sociedade, no entanto nem todos os estudantes contam com pessoas instruídas e com estrutura necessária para ajudá-los.

Sendo assim, na produção dos OVA a equipe LEMAFI está atenta, direcionando o olhar para a linguagem, construção conceitual, visual e formatação. $\mathrm{O}$ que exige envolvimento de praticamente todos os integrantes do LEMAFI, é uma construção acurada, com reflexão e socialização, produções que têm demandado um tempo maior de estruturação que as anteriores. Para Lévy (2003) a inteligência coletiva deve ser incessantemente valorizada, afinal todos podem oferecer conhecimento, basta que se perceba o contexto em que o saber do indivíduo pode contribuir para aquele coletivo.

O mascote, o Lemafinho, nos ajudou para que o material ficasse acessível aos estudantes, fugindo da formalidade dos livros didáticos, mas considerando a rigorosidade dos conceitos matemáticos. Ele rompe com o distanciamento entre os integrantes do grupo e os seguidores. O lúdico chama a atenção, estimula a curiosidade, aguça iniciativas e autoconfiança, proporciona o desenvolvimento do pensamento e da concentração. E em tempos de pandemia, acreditamos que o estudo precisa ser prazeroso e interativo.

Estamos habituados com a interferência verbal do estudante, a postura corporal, situações que nos indicam se precisamos aprofundar as explicações ou buscar recursos complementares. $\mathrm{O}$ plano que trabalhamos em uma aula presencial, de $90 \mathrm{~min}$, foi necessário dividir em duas sequências didáticas. Fato devido a previsão de momentos que teriam dificuldades, e exatamente neste, trazermos o Lemafinho para destacar as informações e conceitos que os ajudassem. Sendo assim, o está permeado por "Fique atento!", "Lembre-se que...", "Para pensar...".

\section{CONCLUSÃO}

A partir das considerações apresentadas, percebemos que estamos constantemente em movimento para o aprender pois este é o resultado da transformação na convivência; aprendemos porque nos colocamos com o outro, legitimamos o saber do outro ao mesmo tempo em que o outro também legitima o nosso. (MATURANA, 2002). Ao produzir Objetos de Aprendizagem - OA - para um espaço de ensino nãoformal da $47^{\mathrm{a}}$ Feira do Livro estávamos vivenciando um emocionar que traz um sentimento de responsabilidade, nos mobilizando para realizar avanços em nosso fazer, mas na zona de conforto, pois era uma atividade rotineira nos espaços educativos formais. Repentinamente, passamos a trabalhar com foco nos Objetos Virtuais de 
Aprendizagem - OVA - para o ensino remoto à emergência, modalidade temporária, com atividades alternativas. Tal fato nos leva a reflexão sobre a relevância de estarmos sempre abertos ao novo, que no nosso caso foi o planejamento de aulas remotas à emergência. Situação que nos desacomodou, levando a recuar para compreender a situação, encontrar outras possibilidades, novos caminhos, chegando a uma segunda zona de conforto (e, assim, sucessivamente).

O estudo possibilitou a percepção da relevância das tecnologias digitais no currículo e na organização das atividades educativas, principalmente em tempos de pandemia. A cultura escolar, diretamente vinculada às tradições e valores da comunidade, neste período histórico passa por transformações. Enquanto formadores de professores, precisamos (re)ver a fluência tecnológica dos discentes da licenciatura e docentes, principalmente de Matemática e Física, e assim, dimensionar as necessidades de suporte para a implementação/utilização de OVA e AVAs, buscando aprimorar as ações do LEMAFI.
Aprendemos que um caminho possível é a reflexão sobre a organização das atividades, um material que não esteja pautado na transmissão pacífica de conceitos, mas que o instigue a reflexão, a pesquisa, a criação de hipóteses e as validar para a construção do seu conhecimento. O que exige do professor a habilidade de agregar afetividade, atentar aos conceitos e procedimentos, habilidades práticas cognitivas e socioemocionais para resolver as demandas cotidianas, mesmo que mediado pela tecnologia e de forma assíncrona

\section{AGRADECIMENTOS}

Agradecemos a Universidade Federal do Rio Grande - FURG e a Secretaria de Município da Educação do Rio Grande - SMEd pela oportunidade de colaborar com as ações de incentivo ao ensino, pesquisa e extensão do Laboratório de Educação Matemática e Física (LEMAFI).

\section{REFERÊNCIAS}

ALMEIDA, W. N. C. A Argumentação e a Experimentação Investigativa no Ensino de Matemática: O Problema das Formas em um Clube de Ciências. 2017. 109 f. Dissertação de mestrado em Docência em Educação em Ciências e Matemáticas Universidade Federal do Pará, Belém. Disponível em: http://repositorio.ufpa.br/jspui/handle/2011/10520.

Acesso em: 17 jun. 2020.

ARAÚJO, L. F. S. de, DOLINA, J. V., PETEAN, E., MUSQUIM, C. dos A., BELLATO, R., LUCIETTO, G. C. Diário de pesquisa e suas potencialidades na pesquisa qualitativa em saúde. Revista Brasileira De Pesquisa Em Saúde/Brazilian Journal of Health Research, v. 15, n. 3, p. 53-61. 2013.

BACICH, L.; TANZI NETO, A.; TREVISANI, F. (Org.). Ensino híbrido: Personalização e tecnologia na educação. Porto Alegre: Penso, 2015.

BERGMANN, J; SAMS, A. Sala de aula invertida: uma metodologia ativa de aprendizagem. (Tradução Afonso C. C. Serra). $1^{\text {a }}$ ed. [reimpr], Rio de Janeiro: LTC, 2020.

BRASIL. Base Nacional Comum Curricular. Educação é a Base. Brasília, MEC/CONSED/UNDIME, 2017. Disponível em: < 568 http://basenacionalcomum.mec.gov.br/images/BNCC_p ublicacao.pdf>. Acesso em: 02 jun. 2017.
BRASIL. Constituição da República Federativa do Brasil: promulgada em 5 de outubro de 1988.

HODGES, C.; MOORE, M.; LOCKEE, B.; TRUST, T.; $\mathrm{BOND}$, A. A diferença entre ensino remoto de emergência e aprendizado on-line. EDUCAUSEREVIEW. Disponível em: https://er.educause.edu/articles/2020/3/the-differencebetween-emergency-remote-teaching-and-on-linelearning\#fn1. Acesso em: 27 jul. 2020.

KENSKI, V. M. Educação e internet no Brasil. Cad. Adenauer, Rio de Janeiro, v. 16, n. 3, p. 133-150, 2015.

LÉVY, P. A inteligência coletiva: por uma antropologia do ciberespaço. 4. ed. São Paulo: Loyola, 2003.

LORENZATO, S. O Laboratório de Ensino de Matemática na Formação de Professores. $3^{\mathrm{a}}$ ed. Campinas, SP: Autores Associados, 2012.

MATURANA, H. R. A Ontologia da Realidade. Belo Horizonte: Ed. UFMG, 2002.

MAZUR, E. Peer Instruction - A Revolução da Aprendizagem Ativa. Editora Penso, 2015.

MORALES, L. S.; MARTINEZ, M. L. S.; GAUTÉRIO, V. L. B.; RODRIGUES, S. C. Do papel à lousa digital: 
explorando conceitos geométricos com o Tangram. In: Débora Pereira Laurino; Daniel da Silva Silveira. (Org.). Projeto Novos Talentos: experiências com tecnologias no ensinar e aprender matemática. 1 ed. Rio Grande: Pluscom Editora, 2016, v. 1, p. 61-82.

MORAN, J. Metodologias ativas para uma aprendizagem mais profunda. In: BACICH, L \& MORAN, J. (Org.). Metodologias Ativas para uma educação inovadora: uma abordagem teóricoprática. Porto Alegre: Penso, 2018.

MUNHOZ, A. S. Vamos inverter a sala de aula? Ed. 1, Clube de Autores, 2015.

NEVES, V. J.; MERCANTI, L. B.; LIMA, M. T. Metodologias Ativas: perspectivas teóricas e práticas no ensino superior. Campinas, SP: Pontes Editora, 2018.

PREFEITURA MUNICIPAL DO RIO GRANDE. Secretaria de Município da Educação do Rio Grande. Documento Orientador Curricular do Território Rio-grandino: ensino fundamental. Rio Grande: SMED, 2019.

PREFEITURA MUNICIPAL DO RIO GRANDE. Lei Orgânica. Art. 161, 02 de abril de 1990. Disponível em: https://leismunicipais.com.br/lei-organica-rio-grande-rs. Acesso em: 27 jul. 2020.

PRENSKY, M.: Digital Natives Digital Immigrants. In: PRENSKY, Marc. On the Horizon. NCB University Press, Vol. 9 No. 5, October (2001a). Disponível em <http://www.marcprensky.com/writing/>. Acesso em: 13 mar 2008.

RÊGO, R. M., RÊGO, R. G. Desenvolvimento e uso de materiais didáticos no ensino de matemática. In: LORENZATO, S. O Laboratório de Ensino de Matemática na Formação de Professores. $3^{\mathrm{a}}$ ed. Campinas, SP: Autores Associados, 2012.

SILVA, R. S. DA; NOVELlO, T. P. O uso das tecnologias digitais no ensinar matemática. Revista Internacional de Educação Superior, v. 6, p. e020025, 23 out. 2019 .

SILVA, I. O. O uso da tecnologia no ensino superior e suas resistências: um estudo de caso na Unileão. Revista Interfaces: saúde, humanas e tecnologia. v. 5, n. 15, p. 71-77, 2017.

SILVA, R. A; CAMARGO, A. L. A cultura escolar na era digital. In: BACICH, L.; TANZI NETO, A.; TREVISANI, F. (Org.). Ensino híbrido: Personalização e tecnologia na educação. Porto Alegre: Penso, 2015.
SILVEIRA, D. S; FONSECA, D. A; LAURINO, D. P. $O$ dar-se conta da formação de professores de matemática no operar de tecnologias digitais no ensino superior. Braz. J. of Develop. Curitiba, v. 5, n. 8, p. 11880-11895 aug.

TARDIF, M. Saberes docentes e formação profissional. 16. ed. Petrópolis: Vozes, 2014. UNIVERSIDADE FEDERAL DO RIO GRANDE FURG. Regimento Geral da (Resolução 015/09, de 26/06/2009 do CONSUN). Disponível em: https:/gerenciamentocosteiro.furg.br/images/Normas/R esolucao-n.-015-2009-CONSUN-FURG-RegimentoGeral-da-FURG.pdf. Acesso em: 27 jul. 2020.

VIGORITO, T. M. S.; GAUTÉRIO, V. L. B. Objetos Virtuais de Aprendizagem na formação Inicial de professores: explorando o ensino de matemática com o uso das TIC. In: JULIANO, A. N.; SILVEIRA, D. da S.; SILVA, R. C. S.; NOVELLO, T. P. (Org.). Educação e Tecnologias na contemporaneidade. 4 ed. Rio Grande: Editora da FURG, 2018, v. 04, p. 71-87.

ZABALA, A. A prática educativa: como ensinar. Porto Alegre: Artmed, 1998. 